\title{
Reumatología clínica
}

www.reumatologiaclinica.org

Carta al Editor

\section{Autoinmunidad en dengue: revisión bibliográfica}

\section{Autoimmunity in dengue: Literature review}

\section{Sr. Editor:}

El presente escrito está en referencia al artículo publicado por Morel y Ramírez ${ }^{1}$, el cual reportó el cuadro clínico de 3 pacientes pediátricos con infección por el virus del dengue (VD) en Paraguay, país endémico de este virus. El primer caso fue un escolar de 8 años, en quién la enfermedad se autolimitó sin recibir tratamiento alguno luego de un tiempo de enfermedad de 14 días caracterizado por fiebre, hepatoesplenomegalia, taquicardia y derrame pleural bilateral con serología positiva para el VD, así como anticuerpos negativos para anticoagulante lúpico, anticardiolipina, anticuerpos antinucleares y anti-DNA, sin anormalidad del complemento. Mientras que los otros 2 casos presentaron un cuadro clínicamente compatible con un síndrome de activación macrofágica (SAM). Un preescolar de 3 años y un lactante de 3 meses quienes tuvieron un cuadro clínico similar, caracterizado por fiebre y hepatoesplenomegalia, además de anemia, leucopenia y neutropenia, con respuesta favorable a tratamiento con glucocorticoides ${ }^{1}$. El SAM es clínicamente presentado con citopenia, disfunción de órganos y coagulopatías debido a la inactivación inapropiada de los macrófagos. El SAM ha sido relacionado a trastornos autoinmunes en diversas enfermedades, principalmente en la artritis idiopática juvenil sistémica, pero también con otros procesos autoinmunes ${ }^{2}$. Además, se ha reportado otro caso de SAM asociado a infección por dengue; donde Lai et al. reportaron a una mujer de 55 años con neutropenia, linfopenia, además de un mielograma con evidencia de hemofagocitosis. Durante su hospitalización fue diagnosticada de síndrome nefrótico donde se confirmó la infección por dengue con positividad del antígeno NS1 y serología IgG e IgM positiva, el cual demostró una reinfección del $\mathrm{VD}^{3}$.

También se han reportado otros casos de asociación de manifestaciones autoinmunes e infección por el VD. Así Talib et al. han reportado un caso de lupus eritematoso sistémico (LES) y nefritis lúpica desencadenado por el VD, en donde la prueba serológica antígeno NS1 fue positivo. Para la confirmación del LES con nefritis lúpica se cumplieron 4/11 criterios diagnósticos del American College of Rheumatology, entre ellos el anticuerpo antinuclear con patrón homogéneo y el anti-dsDNA positivo ${ }^{4}$. Se encontraron escasos reportes sobre la interrelación del VD con nefritis lúpica y el LES, sin embargo dicho caso pudo tener relación a una nefropatía asociada a un p-ANCA positivo o por haberse desarrollado como un brote lúpico o una enfermedad de novo. Otro reporte, en China, encontró asociación entre el VD y las manifestaciones oculares asociado en mujeres jóvenes, en donde la infección por el VD incitó a la producción de anticuerpos y formación de depósitos de inmunocomplejos, desarrollando una vasculitis retiniana posterior ${ }^{5}$.

La producción de anticuerpos cumplió un rol importante en la patogénesis del dengue. Diversos estudios en modelos animales y pacientes hospitalarios han mostrado que la generación de autoanticuerpos contra plaquetas, células endoteliales y factores de coagulación se correlacionaron con la severidad de la enfermedad y al desarrollo de fiebre hemorrágica ${ }^{6,7}$. Particularmente, se ha reportado que los títulos de los anticuerpos para células endoteliales, analizados por citometría de flujo alcanzaron niveles máximos durante la fase aguda, disminuyendo posteriormente; aún así fueron detectables durante varios meses, lo que la diferencia de otras infecciones crónicas. Los niveles de autoanticuerpos fueron superiores para aquellos pacientes que tuvieron fiebre hemorrágica o síndrome de shock por dengue en comparación con los infectados por DV, además que estos niveles de autoanticuerpos eran similares entre los serotipos DEN-2, 3 y $4^{8}$. Otro estudio reportó la persistencia de síntomas clínicos 2 años después de la infección aguda asociado a niveles altos persistentes de IgG, polimorfismo genético de FcyRIIa, en conjunto con presencia de inmunocomplejos o positividad de anticuerpos antinucleares, factor reumatoide, o niveles elevados de proteína $C$ reactiva ${ }^{9}$.

Se recomienda a los países de zonas endémicas no olvidar tener al VD como diagnóstico diferencial ante cualquier enfermedad sistémica, más aún si es en población pediátrica, ya que la literatura revisada demostró un incremento de atipia en la sintomatología. Manifestaciones reportadas en casos clínicos atípicos de países endémicos están relacionados a presentaciones sistémicas, que incluyen problemas hepáticos (27\%), colecistitis alitiásica (9\%), pancreatitis (9\%), problemas pulmonares (9\%) y cardiovasculares $(7 \%)^{10}$.

En conclusión, consideramos un importante aporte la contribución de Morel y Ramírez ${ }^{1}$, los cuales complementaron otros reportes previos de asociación entre autoinmunidad clínicamente manifiesta y la infección por el VD previamente descritos. Resultando importante, por ende, realizar mayores estudios en poblaciones endémicas para esta enfermedad a fin de tener una mejor caracterización de las posibles consecuencias de la exacerbación autoinmune que pueda ocurrir en estos sujetos a largo plazo.

\section{Conflicto de intereses}

Los autores declaran no tener ningún conflicto de intereses.

\section{Bibliografía}

1. Morel Z, Ramírez A. Respuesta autoinmune en niños con dengue. Reporte de casos. Reumatol Clin. 2014;10:257-9. 
2. Deane S, Selmi C, Teuber S, Gershwin M. Macrophage activation syndrome in autoimmune disease. Int Arch Allergy Immunol. 2010;153:109-20.

3. Lai M, Stirnemann J, Bibi-Triki T, Gerin M, Brichler S, Prendki V, et al. Dengue fever complicated by a nephrotic syndrome and a hemophagocytic syndrome [Article in French]. Med Mal Infect. 2012;42:30-2.

4. Talib SH, Bahattu SR, Bhattu R, Deshpande SG, Dahiphale DB. Dengue fever triggering systemic lupus erythematosus and lupus nephritis: A case report. Int Med Case Rep J. 2013;6:71-5.

5. Chang J, Cheng C, Asok K, Fong K, Chee S, Tan C. Visual disturbances in dengue fever an answer at last? Singapore Med J. 2007;48:e71-3.

6. Saito M, Oishi K, Inoue S, Dimaano EM, Alera MT, Robles AM, et al. Association of increased platelet-associated immunoglobulins with thrombocytopenia and the severity of disease in secondary dengue virus infections. Clin Exp Immunol. 2004:138:299-303

7. Wan SW, Lin CF, Yeh TM, Liu CC, Liu HS, Wang S, et al. Autoimmunity in dengue pathogenesis. J Formos Med Assoc. 2013;112:3-11.

8. Wan SW, Lin CF, Yeh TM, Liu CC, Liu HS, Wang S, et al. Autoimmunity in dengue pathogenesis. J Formos Med Assoc. 2013;112:3-11.
9. García G, González N, Pérez AB, Sierra B, Aguirre E, Rizo D, et al. Long-term persistence of clinical symptoms in dengue-infected persons and its association with immunological disorders. Int J Infect Dis. 2011;15:e38-43.

10. Stave K. Herrera E. Manifestaciones clínicas inusuales del dengue hemorrágico en niños. Rev Cienc Biomed. 2013;4:69-74.

Fernando Palacios-Cuervo, Andrea Calderón-Rivera*, Fátima Espinal-Reyes y Carlos Canelo-Aybar

Escuela de Medicina, Universidad Peruana de Ciencias Aplicadas, Lima, Perú

* Autor para correspondencia.

Correo electrónico: f.calderonrivera89@gmail.com (A. Calderón-Rivera). 